\title{
Expression of pigment epithelial derived factor is reduced in non-small cell lung cancer and is linked to clinical outcome
}

\author{
LIJIAN ZHANG ${ }^{1}$, JINFENG CHEN $^{1}$, YANG KE $^{2}$, ROBERT E. MANSEL ${ }^{3}$ and WEN G. JIANG ${ }^{3}$ \\ ${ }^{1}$ Department of Surgery, Peking University School of Oncology, No. 52 Fu-cheng Road, Haidian District; \\ ${ }^{2}$ Department of Cell Biology, Health Science Center, Peking University, No. 38 Xueyuan Road, Hai Dian District, Beijing, \\ P.R. China; ${ }^{3}$ Metastasis and Angiogenesis Research Group, Wales College of Medicine, Cardiff University, Cardiff, UK
}

Received November 8, 2005; Accepted December 28, 2005

\begin{abstract}
Angiogenesis is under the exquisite control of a network of angiogenic factors and anti-angiogenic factors. PEDF (pigment epithelial derived factor) is one of the known anti-angiogenesis factors and is naturally occurring in the body. There has been studies to show that the factor plays an important role in negating the angiogenic process in pathological conditions in the eye. However, little is known about its expression in solid tumors. The current study examined PEDF expression at protein and message levels and investigated its critical link with cancer progression and prognosis in patients with non-small cell lung cancer (NSCLC). We used immunohistochemistry to examine the protein expression of PEDF and to evaluate the micro-vessel density (MVD) in a cohort of 91 NSCLC patients. In addition, realtime quantitative PCR was used to measure levels of the PEDF transcript. PEDF was positively stained in cytoplasm of cancer cells, but at a lower level, compared with normal cells in the lung tissues. Low levels of PEDF were seen in 57.1\% patients. The levels of PEDF appeared to be associated with MVD, in that patients with reduced PEDF had a significantly high MVD count (28.50), compared with patients with high levels of PEDF who had a 16.98 MVD count $(\mathrm{P}<0.0005)$. In univariate but not multivariate analysis PEDF was an independent prognostic factor. In real-time PCR analysis, PEDF mRNA level of cancer tissue was significantly lower than normal tissue $(0.55 \pm 0.36$ vs $0.72 \pm 0.26, \mathrm{P}=0.024$, paired t-test). PEDF mRNA level in cancer tissue was negatively associated with TNM stage and the tumor size $(\mathrm{P}<0.05$, independent t-test). Finally, low levels of PEDF in lung tumor tissues was associated with a significantly shorter survival $(\mathrm{P}=0.038)$ using Kaplan-Meier and Cox analyses. In this first study, PEDF was reduced at both protein and mRNA level in NSCLC tumors compared with normal lung tissues. This reduction is associated with an increase in micro-
\end{abstract}

Correspondence to: Dr Wen G. Jiang, Metastasis and Angiogenesis Research Group, Wales College of Medicine, Cardiff University, Heath Park, Cardiff CF4 4XN, UK

E-mail: jiangw@cf.ac.uk

Key words: pigment epithelial derived factor, non-small cell lung cancer, metastasis, survival, prognosis, micro-vessel density, angiogenesis vessel density in tumors and significantly associated with TNM stage, tumor size and the overall survival. PEDF is an important factor in NSCLC development and may be a of prognostic value for NSCLC patients.

\section{Introduction}

PEDF (pigment epithelial derived factor) is a protein with MW $50 \mathrm{kDa}$, encoded by the EPC-1 gene (1). It is a glycoprotein composed of 418-aa, of which four (glutamate-101, isoleucine-103, leucine-112, and serine-115) in the 44-aa region, has been found critical for its anti-vasopermeability activity (2), i.e. ability to counteract VEGF-induced vascular permeability. It is expressed in normal tissue throughout the body $(3,4)$. It was first discovered in 1989 as a neurotrophic serpin (serine protease inhibitor) that was secreted by retinal pigment epithelial cells $(5,6)$. As a secreted glycoprotein, PEDF is expressed in adult liver, testis, ovaries, placenta, brain and pancreas (7). PEDF has been previously shown to have neurotrophic activity. In sequence and structure, PEDF resembles members of the serine protease inhibitor family, but lacks protease inhibitor activity. PEDF therefore has been seen as a member of the serine protease inhibitor (serpin) family (8).

PEDF has been shown to be a potential and novel antiangiogenic factor in a limited number of studies. It can inhibit endothelial cell migration and proliferation and reduce choroidal and retinal neovascularization (5,9-11). Thus far, PEDF has been shown to have strong anti-angiogenesis effect on at least a comparable basis with factors, such as angiostatin, thrombospondin-1 and endostatin $(5,12)$. PEDF has been shown to regulate blood vessel growth in the eye by creating a permissive environment for angiogenesis when oxygen supply is limited, and creating an inhibitory environment when oxygen concentrations are normal or high. In human solid tumors, there has been very little study on the expression and clinical significance of PEDF. Using immunohistochemistry to investigate the expression of PEDF in ductal pancreatic adenocarcinoma patients, a correlation between PEDF and MVD, and clinical pathological factors and prognosis was reported (13). Although there has been no studies on the expression of PEDF in lung cancer, we have recently reported that PEDF is actively involved in the regulation of lung cancer induced angiogenesis in vitro (14). 
In the present study, we used immunohistochemical staining and a real-time quantitative PCR assay to measure PEDF protein and message, respectively, in lung cancer, and attempted to establish if a link existed between PEDF and non-small cell lung cancer and patients clinical outcome.

\section{Materials and methods}

Patients and samples. A total of 91 patients with non-small cell lung cancer, who did not receive any adjuvant therapy prior to surgical operation, at Beijing Cancer Hospital from July 2000 to August 2003, were included in this study. Histological types of these lung cancers included squamous carcinoma (42 cases), adenocarcinoma (33 cases), adenosquamous carcinoma (6 cases), large cell carcinoma ( 2 cases), carcinoid ( 2 cases), alveolar carcinoma (6 cases). No other previous or concomitant primary cancer was present. Clinicopathological characteristics were defined according to TNM criteria of UICC (15). Clinical and pathological information including age, sex, histological types of tumors, tumor cell grade, TNM stage, vessel embolism, lymph node metastasis, were reviewed and stored in a database. Patients were followed up from the day of their operation to August 2004. The follow-up intervals were calculated as survival intervals after surgery. Ethical approval and informed consents were obtained from the local ethics committee and patients respectively.

Fresh tissue samples were obtained from 21 primary nonsmall cell lung cancers, resected surgically from patients at Clinical Oncology School of Peking University from 2002 to 2003. The tissues were immediately collected after surgery, frozen in liquid nitrogen and stored at $-80^{\circ} \mathrm{C}$ for RNA extraction. Surrounding normal lung tissues $(>5 \mathrm{~cm}$ away from the tumor margin) were also collected. These cohorts include 13 men and 8 women, with a mean age of 56.2 \pm 6.4 years. The histological type of lung cancer was classified based on the World Health Organization method (16). Tumor staging was performed according to the TNM staging criteria of the UICC (15). The histological type of this collection included 10 squamous cell carcinomas, 8 adenocarcinomas, and 3 undifferentiated carcinomas. Tumor staging was I in 3 cases, II in 7 cases, IIIA or IIIB in 10 cases, and IV in 1 case.

Materials. A goat polyclonal antibody of PEDF and a mouse monoclonal antibody of $\beta$-actin were purchased from Santa Cruz Biotechnology Inc. (Santa Cruz, CA, USA). Mouse monoclonal antibody of CD31 was purchased from Beijing Zhongshan Biotechnology Co. Ltd. (Beijing, China). The biotin conjugated anti-goat $\mathrm{IgG}$, anti-mouse IgG antibodies were purchased from Sigma (Poole, Dorset, UK). The Target Retrieval Solution was purchased from Dako Corp. RNA extraction and reverse transcription kits and PCR mix were purchased from Bio-Rad Corp. Primers were synthesized by BioAsia Corp. (Shanghai, China).

PEDF staining and micro-vessel counting. The paraffinembedded tissue sections of 91 patients were cut at $4 \mu \mathrm{m}$ and mounted on polylysin-coated glass slides for immunohistochemistry. Deparaffinized sections were first heated at $60^{\circ} \mathrm{C}$ for $1 \mathrm{~h}$. Antigen retrieval was performed by heating the samples without boiling in Target Retrieval Solution, pH 6.7 $(200 \mathrm{ml})$ in a microwave oven for $10 \mathrm{~min}$. After endogenous peroxidase was blocked with $3 \%$ hydrogen peroxide, each section was incubated with non-immunised horse serum (Sigma) for $15 \mathrm{~min}$, in order to block the non-specific antigen site. The immunohistochemical staining procedure was performed according to manufacturer's protocol. The primary anti-PEDF and anti-CD31 antibodies were used at a dilution 1:100 from the stock. Following incubation at $4^{\circ} \mathrm{C}$ overnight, the sections were extensively washed and then incubated with the respective link antibody. Following extensive washing, bound antibodies were linked to avidinbiotin-peroxidase according to the instruction of Dako Corp., followed by developing colour using a DAB (diaminobenzidine tetrahydrochloride) solution for $5 \mathrm{~min}$. The slides were counterstained with Mayers hematoxylin blue in $0.3 \%$ ammonia. For negative controls, sections were stained in the same manner, except that the primary antibody was absent from the solution.

Evaluation of PEDF staining and the micro-vessel density counting. PEDF staining in lung cancer cells was independently assessed by two observers using a modification of the system of grading the relative intensity of immunoreactivity for the respective antibodies $(17,18)$. PEDF immunohistochemical staining of a tissue sample was graded as either low level (patchy and weak or negative immunoreactivity) or high level (uniformly intense immunoreactivity).

Micro-vessel density (MVD) was evaluated according to a method recently described $(18,19)$. After screening the areas with intense neovasularized spots at low power field (x100), microvessels in the area with the highest number of discrete microvessels were counted in a $\times 400$ field. Three separate areas with intense neovascularisation were assessed for each 'hot' spot, and the mean was calculated as MVD of each tumor evaluated. The MVD levels were graded as low with MVD number $<26$, and as high with MVD number $>26$.

Generation of cDNA from fresh frozen NSCLC tissue and normal tissue and RT-PCR. RNA was extracted from tumor and the matched normal surrounding tissues in RNA extraction buffer using the standard guanidine isothiocyanate method by following the manufacturer's protocol and as we previously reported (20). Reverse transcription was performed from $1 \mu \mathrm{g}$ of total RNA using oligo dt primer according to the manufacturer's instructions.

Conventional PCR primers were designed using primer 3 (http://frodo.wi.mit.edu/cgi-bin/primer3/primer3_www.cgi), to allow amplification of regions that have no overlap with other known genes and span at least one intron. Sequences for the PEDF primers are: 5'-CGATGAGATCAGCATTC TCC-3' and 5'-ATTCTGGGTCACTTTCAGGG-3' (product size $256 \mathrm{bp}$ ); and for the GAPDH primers: 5'-AGGTCGGAG TCAACGGATTTG-3' and 5'-GTGATGGCATGGACTG TGGT-3' (product size $532 \mathrm{bp}$ ). Conventional PCR was with the following conditions: $95^{\circ} \mathrm{C} 5 \mathrm{~min}, 94^{\circ} \mathrm{C}$ for $1 \mathrm{~min}, 55^{\circ} \mathrm{C}$ for $45 \mathrm{sec}, 72^{\circ} \mathrm{C}$ for $30 \mathrm{sec}$ and a final extension phase at $72^{\circ} \mathrm{C}$ for $7 \mathrm{~min}$ for 40 cycles. The PCR products were separated on a $2 \%$ agarose gel and stained with $5 \mu 1$ ethidium bromide prior to examination under UV light and photographs taken. 

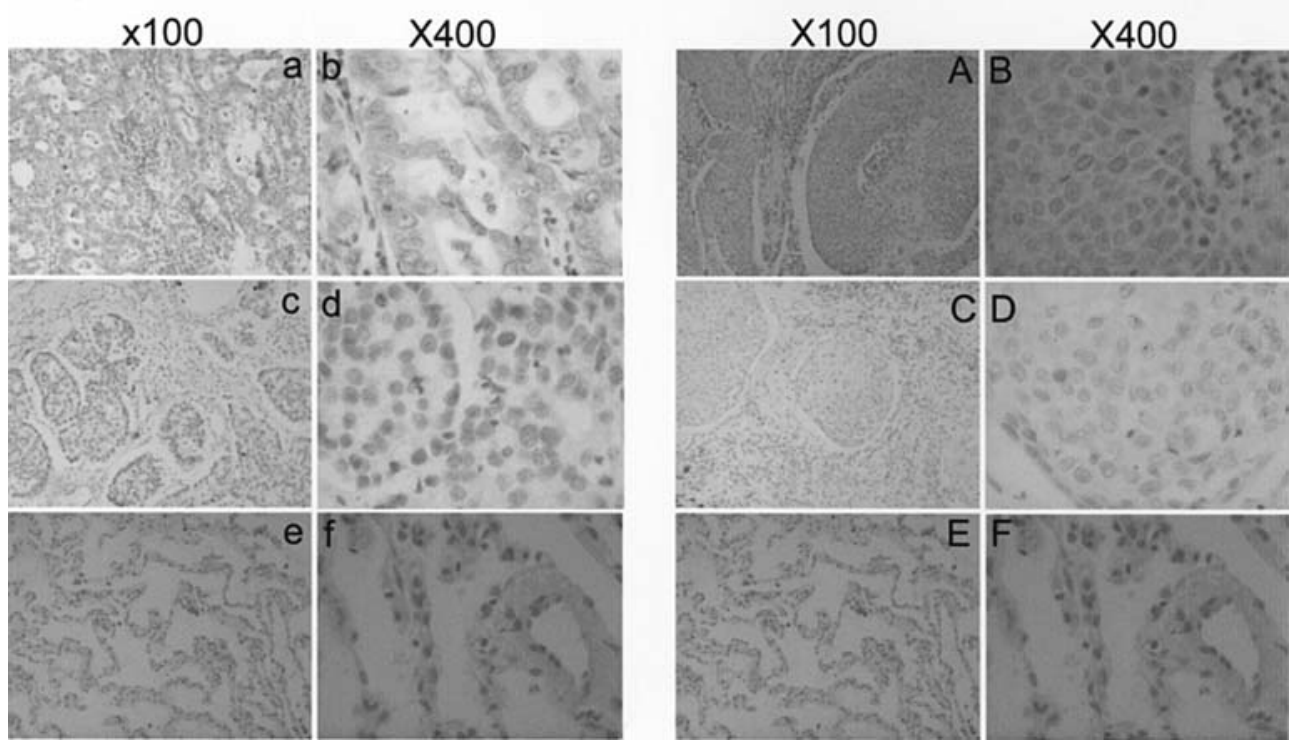

Figure 1. Immunohistochemical staining for PEDF in adenocarcinoma (a-d) and squamous carcinoma (E-D) and in normal lung tissues (e and f). (a/A and b/B) Showed a diffuse cytoplasmic staining of PEDF in adenocarcinoma of lung. (c/C and d/D) Showed a negative staining in adenocarcinoma of lung. (e/E and f/F) Showed a positive staining status of PEDF in alveoli. Original magnification: x100 for the left panel and x 400 for the right panel.

Preparation of real-time PCR standard and real-time quantitative RT-PCR analysis for PEDF transcript. The procedure was similar to a method recently described (21). The PCR product from the above reaction was gel-excised and purified using a gel purification kit (Tianwei Corp., Beijing). It was subsequently quantified on a gel with lambda molecular weight standards and in a spectrophotometer. The number of copies of target template was later calculated. The DNA sample was serially diluted to yield a concentration range between $10^{2}$ and $10^{8}$ copies, which was subsequently used as an internal standard for quantitation. This was finally prepared in elution buffer, aliquated and stored at $-80^{\circ} \mathrm{C}$ until use.

The iCycler $\mathrm{iQ}^{\mathrm{TM}}$ system incorporates a gradient thermocycler and a 96-channel optical unit. SYBR Green, which is a fluorescence dye only for dsDNA, was used to detect the PCR product of PEDF and GAPDH $(22,23)$. Quantitative PCR was carried out in a 96-well plate with 10 pmol foward and reverse primers, and the working solution of SYBR Green, using a customer PCR master mix, with the following conditions: $95^{\circ} \mathrm{C}$ for $5 \mathrm{~min}$, followed by 40 cycles at $95^{\circ} \mathrm{C}$ for $1 \mathrm{~min}, 55^{\circ} \mathrm{C}$ for $45 \mathrm{sec}, 72^{\circ} \mathrm{C}$ for $30 \mathrm{sec}$. Detection of fluorescence signal was at extension stage. The copy number of each transcript was calculated as the relative copy number normalized by GAPDH copy number. Every assay included test cDNA samples, 10-fold serial dilutions of the standard qualification, and controls (no template).

The optimum temperature and the specificity of the analysis based on SYBR Green method were pre-determined using the melting temperature curve. The specificity was further confirmed by agarose gel electrophoresis.

Statistic analysis. Chi-square analysis was used to test the association of PEDF expression level with standard pathological variations. Clinical pathological parameters and PEDF expression status were correlated with survival time in both univariate and multivariate analyses. Variables included in univariate analysis were MVD, PEDF, gender, TNM stage, grade of differentiation, vessel cancer embolus, lymph nodal status and use of postoperative adjuvant therapy. Variables included in multivariate analysis were MVD, PEDF expression status, gender, TNM stage, grade of differentiation, vessel cancer embolus, lymphatic nodal status and use of postoperative adjuvant therapy. The log-rank test was used to test equality across categorical factors in univariate analysis, and the level of significance was set at $\mathrm{P} \leq 0.05$ based on twosided test. The multivariate analysis was performed using Cox proportional hazards model, and the level of significance was set at $\mathrm{P} \leq 0.05$ based on two-sided test.

Paired-sample analysis was used (Student's t-test) to determine the difference of PEDF mRNA expression level observed between matched cancer tissue and the normal tissue. Independent-samples analysis was used (Student's t-test) to determine the differences observed between PEDF expression level in NSCLC tissue and the clinicopathological characteristics. Statistical tests were performed using the software SPSS 10.0 (SPSS Inc., Chicago, IL).

\section{Results}

Immunohistochemical analysis and the localization of PEDF in lung cancer. The staining pattern for PEDF was mainly in the cytoplasm. In both adenocarcinoma (Fig. 1a and b) and squamous cell carcinoma of lung (Fig. 1A and B) the staining was diffuse and weaker, when compared with normal lung tissues (Fig. 1e and f, Fig. 1E and F).

PEDF and the clinical correlation. The immunohistochemical staining results of PEDF in NSCLC are shown in Table I. Low level expression of PEDF in NSCLC was found in 48 (52.7\%) cases. Amongst the available clinical parameters, tumor grade was the only one showning a significant correlation with PEDF $(\mathrm{P}=0.016)$, while others failed to reach a significant correlation $(\mathrm{P}>0.05)$. 
Table I. Tumor expression of PEDF vs clinicopathologic features in the complete series $(n=91)$.

\begin{tabular}{|c|c|c|c|c|c|}
\hline \multirow[b]{2}{*}{ Variable } & \multirow[b]{2}{*}{$\begin{array}{c}\text { Cases } \\
(\%)\end{array}$} & \multicolumn{3}{|c|}{ PEDF expression } & \multirow[b]{2}{*}{$\begin{array}{c}\text { P-value } \\
\left(\chi^{2}\right)\end{array}$} \\
\hline & & \multicolumn{2}{|c|}{$\begin{array}{c}\text { Low } \\
\text { expression }\end{array}$} & $\begin{array}{c}\text { Over- } \\
\text { expression }\end{array}$ & \\
\hline \multicolumn{6}{|l|}{ Sex } \\
\hline Men & 63 & $69.2)$ & 35 & 28 & \multirow[t]{2}{*}{0.498} \\
\hline Women & 28 & 30.8) & 13 & 15 & \\
\hline \multicolumn{6}{|l|}{ Age } \\
\hline$\leq 60$ & 43 & 47.3) & 21 & 22 & \multirow[t]{2}{*}{0.532} \\
\hline$>60$ & 48 & 52.7) & 27 & 21 & \\
\hline \multicolumn{6}{|l|}{ Histological type } \\
\hline $\begin{array}{l}\text { Squamous } \\
\text { carcinoma }\end{array}$ & 42 & 46.2) & 24 & 18 & \multirow{6}{*}{0.054} \\
\hline Adenocarcinoma & 33 & 36.3) & 15 & 18 & \\
\hline $\begin{array}{l}\text { Adenosquamous } \\
\text { carcinoma }\end{array}$ & & $6.6)$ & 6 & 0 & \\
\hline Large cell carcinoma & & 2.2) & 0 & 2 & \\
\hline Carcinoid & & 2.2) & 0 & 2 & \\
\hline Alveolar carcinoma & & 6.6) & 3 & 3 & \\
\hline \multicolumn{6}{|l|}{$\begin{array}{l}\text { Grade of } \\
\text { differentiation }\end{array}$} \\
\hline Poor & 11 & 12.1) & 5 & 6 & \multirow{3}{*}{0.016} \\
\hline Moderate & 48 & 51.7) & 32 & 16 & \\
\hline Well & 32 & $35.2)$ & 11 & 21 & \\
\hline \multicolumn{6}{|l|}{ Tumor size } \\
\hline $\mathrm{T} 1$ & & 9.9) & 4 & 5 & \multirow{4}{*}{0.822} \\
\hline $\mathrm{T} 2$ & 60 & 65.9) & 32 & 28 & \\
\hline $\mathrm{T} 3$ & 19 & 20.9) & 11 & 8 & \\
\hline $\mathrm{T} 4$ & & 3.3) & 1 & 2 & \\
\hline \multicolumn{6}{|l|}{ Nodal status } \\
\hline N (-) & 49 & 53.8) & 22 & 27 & \multirow[t]{2}{*}{0.141} \\
\hline $\mathrm{N}(+)$ & 42 & 46.2) & 26 & 16 & \\
\hline \multicolumn{6}{|l|}{$\begin{array}{l}\text { Vessel cancer } \\
\text { embolus }\end{array}$} \\
\hline $\mathrm{V}(-)$ & 67 & 73.6) & 34 & 33 & \multirow[t]{2}{*}{0.635} \\
\hline $\mathrm{V}(+)$ & 24 & 26.4) & 14 & 10 & \\
\hline \multicolumn{6}{|l|}{ TNM stage } \\
\hline I & 40 & 43.9) & 16 & 24 & \multirow{5}{*}{0.191} \\
\hline II & 20 & 22.0) & 11 & 9 & \\
\hline IIIa & 28 & 30.8) & 19 & 9 & \\
\hline IIIb & & 1.1) & 1 & 0 & \\
\hline IV & & 2.2) & 1 & 1 & \\
\hline
\end{tabular}

Micro-vessel density in lung cancer and its correlation with $P E D F$. Micro-vessel endothelial cells were positively stained for CD31. The correlation between MVD number and the clinicopathologic features in NSCLC are shown in Table II.
Table II. Micro-vessel density counting vs clinicopathologic features in the complete series $(n=91)$.

\begin{tabular}{|c|c|c|c|c|}
\hline \multirow[b]{2}{*}{ Variable } & \multirow[b]{2}{*}{$\begin{array}{c}\text { Cases } \\
(\%)\end{array}$} & \multicolumn{2}{|c|}{ MVD } & \multirow[b]{2}{*}{$\begin{array}{c}\text { P-value } \\
\left(\chi^{2}\right)\end{array}$} \\
\hline & & Low & High & \\
\hline \multicolumn{5}{|l|}{ Sex } \\
\hline Men & $63(69.2)$ & 37 & 26 & \multirow[t]{2}{*}{0.654} \\
\hline Women & $28(30.8)$ & 15 & 13 & \\
\hline \multicolumn{5}{|l|}{ Age } \\
\hline$\leq 60$ & $43(47.3)$ & 24 & 19 & \multirow[t]{2}{*}{0.835} \\
\hline$>60$ & $48(52.7)$ & 28 & 20 & \\
\hline \multicolumn{5}{|l|}{ Histological type } \\
\hline Squamous carcinoma & $42(46.2)$ & 24 & 18 & \multirow{7}{*}{0.312} \\
\hline Adenocarcinoma & $33(36.3)$ & 20 & 13 & \\
\hline Adenosquamous & $6(6.6)$ & 2 & 4 & \\
\hline carcinoma & & & & \\
\hline Large cell carcinoma & $2(2.2)$ & 2 & 0 & \\
\hline Carcinoid & $2(2.2)$ & 0 & 2 & \\
\hline Alveolar carcinoma & $6(6.6)$ & 4 & 2 & \\
\hline \multicolumn{5}{|l|}{$\begin{array}{l}\text { Grade of } \\
\text { differentiation }\end{array}$} \\
\hline Poor & $11(12.1)$ & 7 & 4 & \multirow{3}{*}{0.345} \\
\hline Moderate & $48(52.7)$ & 24 & 24 & \\
\hline Well & $32(35.2)$ & 21 & 11 & \\
\hline \multicolumn{5}{|l|}{ Tumor size } \\
\hline $\mathrm{T} 1$ & $9(9.9)$ & 5 & 4 & \multirow{4}{*}{0.988} \\
\hline $\mathrm{T} 2$ & $60(65.9)$ & 34 & 26 & \\
\hline $\mathrm{T} 3$ & $19(20.9)$ & 11 & 8 & \\
\hline $\mathrm{T} 4$ & $3(3.3)$ & 2 & 1 & \\
\hline \multicolumn{5}{|l|}{ Nodal status } \\
\hline N (-) & $49(53.8)$ & 29 & 20 & \multirow[t]{2}{*}{0.678} \\
\hline $\mathrm{N}(+)$ & $42(46.2)$ & 23 & 19 & \\
\hline \multicolumn{5}{|l|}{$\begin{array}{l}\text { Vessel cancer } \\
\text { embolus }\end{array}$} \\
\hline $\mathrm{V}(-)$ & $67(73.6)$ & 39 & 28 & \multirow[t]{2}{*}{0.812} \\
\hline $\mathrm{V}(+)$ & $24(26.4)$ & 13 & 11 & \\
\hline \multicolumn{5}{|l|}{ TNM stage } \\
\hline I & $40(44.0)$ & 27 & 13 & \multirow{5}{*}{0.389} \\
\hline II & $20(22.0)$ & 10 & 10 & \\
\hline IIIa & $28(30.8)$ & 14 & 14 & \\
\hline IIIb & $1(1.1)$ & 0 & 1 & \\
\hline IV & $2(2.2)$ & 1 & 1 & \\
\hline
\end{tabular}

Low level of MVD in NSCLC was found in $52(57.1 \%)$ cases. Amongst the available clinical parameters, no clinical factors showed significant correlation with CD31 as shown in Table II $(\mathrm{P}>0.05)$. 
Table III. The correlation between PEDF and microvascular density.

\begin{tabular}{lcccc}
\hline $\begin{array}{l}\text { PEDF } \\
\text { expression }\end{array}$ & Cases & Mean \pm SD & Standard error & P-value \\
\hline Low & 48 & $28.50 \pm 8.22$ & 1.19 & $<0.0005$ \\
High & 43 & $16.98 \pm 6.15$ & 0.94 & \\
\hline
\end{tabular}

Table III shows the correlation between PEDF and MVD. The mean MVD counts were 28.5 \pm 8.2 (mean \pm 8 SD) for the 43 patients who had low-level PEDF staining. MVD counts for the 43 high-level PEDF was 16.98 \pm 6.15 . The difference between these two groups was highly significant $(\mathrm{P}<0.0005)$.

Clinical outcome and prognostic value of variables. The median time of follow-up for the cohort $(n=91)$ was 24.6 months (range 2-49 months). The mean (SD) survival time was $23.1 \pm 14.4$ months. Cumulative survival curves were calculated using the Kaplan-Meier method. Univariate analysis of the impact of histological types on PEDF expression status is presented in Table IV. Longer survival time was found to be significantly correlated with the following factors: low TNM stage $(\mathrm{P}=0.0005)$, node negative (mean survival time, 41.04 months vs 31.25 months for node positive, $\mathrm{P}=0.0051$ ), low MVD (39.96 months vs 31.85 months with high MVD, $\mathrm{P}=0.0434)$, high-level PEDF (40.56 months vs 32.41 months vs low PEDF, $\mathrm{P}=0.0378$ ) (Fig. 2, top A).

A multivariate prognostic analysis based on the Cox proportional hazard model showed that amongst all the available indicators, TNM stage was the only independent prognostic factors ( $\mathrm{P}=0.004$, respectively).

Survival analysis using Kaplan-Meier survival curve based on PEDF is shown in Fig. 2 (top), in that cumulative survival time for patients with high-level PEDF (Fig. 2, top A; n=43) was significantly longer than those with low-level PEDF $(\mathrm{n}=43)$ (Fig. 2, top B; $\mathrm{P}=0.0378)$. Significantly shorter survival time was also seen in patients with node positive tumors $(n=42), P=0.0051$, vs node negative tumors $(n=49)$ (Fig. 2, middle). Furthermore, survival difference between patients with low MVD ( $=52)$ and high MVD ( $=43)$ was significant ( $\mathrm{P}=0.0434)$ (Fig. 2, bottom).

PEDF mRNA expression level in NSCLC and normal lung tissue assessed by real-time RT-PCR. We have generated an internal standard curve for the quantitative analysis of PEDF and GAPGH. The regression coefficients for the regression lines plotting the threshold cycle $\left(\mathrm{C}_{\mathrm{T}}\right)$ against the starting amount of the standard sample were 0.997, 0.997, for GAPDH and PEDF respectively. Both the reaction curve and the melting curve confirmed that the amplification products for these molecules were specific. This standard was subsequently used to deduce the transcript numbers of PEDF which is shown in the current report as copy number of PEDF mRNA/copy number of GAPDH mRNA.

The relative copy number for PEDF in 21 samples of lung cancer tissue ranged from 0.11 to 1.11 , with a mean \pm SD of
Table IV. Potential prognostic factors using univariate analysis.

\begin{tabular}{lll}
\hline Characteristics & Pts. Mean survival time & P-value from
\end{tabular}

(months) log-rank test

Sex

Male

Female

$63 \quad 36.42(31.77-41.08)$

0.8860

TNM stage

$\begin{array}{lrc}\text { I } & 40 & 41.61(37.35-45.87) \\ \text { II } & 20 & 38.44(31.18-45.70) \\ \text { IIIa } & 28 & 30.31(22.76-37.86) \\ \text { IIIb } & 1 & 6.00(6.00-6.00) \\ \text { IV } & 2 & 13.50(3.11-23.89)\end{array}$

0.0005

Grade of

differentiation

$\begin{array}{llll}\text { Well } & 32 & 37.43(31.17-43.69) & \\ \text { Moderate } & 48 & 34.76(29.86-39.67) & 0.4984 \\ \text { Poor } & 11 & 39.73(28.34-51.12) & \end{array}$

Poor

$11 \quad 39.73(28.34-51.12)$

Nodal status

$\mathrm{N}(-) \quad 49 \quad 41.04(36.64-45.45)$

0.0051

$\mathrm{N}(+)$

$42 \quad 31.25(25.64-36.86)$

Vessel cancer

embolus

$\begin{array}{lll}\text { V (-) } & 67 & 37.50(33.41-41.58) \\ \text { V (+) } & 24 & 33.89(25.75-42.03)\end{array}$

Postoperative adjuvant therapy No

$26 \quad 37.47(29.70-45.24)$

0.7225

Chemotherapy

$65 \quad 36.03(31.57-40.49)$

or radiation

MVD

High

Low

$39 \quad 31.85(25.68-38.03)$

0.0434

$52 \quad 39.96(35.48-44.44)$

PEDF staining

Low expression $\quad 48 \quad 32.41$ (26.72-38.09)

0.0378

Over-expression $\quad 43 \quad 40.56(35.92-45.21)$

$0.55 \pm 0.36$, while the corresponding values in the matched normal lung tissue ranged from 0.29 to 1.31 , with a mean \pm $\mathrm{SD}$ of $0.72 \pm 0.26$. PEDF mRNA expression level in normal tissue was significant higher than in the matched cancer tissue (95\% CI: $2.530 \mathrm{E}-02-0.3176, \mathrm{P}=0.024$, paired t-test), in that $16 / 21(76 \%)$ of tumor samples had lower levels of PEDF transcript than their matched healthy lung tissues and 5/21 $(26 \%)$ had higher levels.

Relationship between PEDF mRNA expression and clinicopathologic variables. Table $\mathrm{V}$ shows the relationship between PEDF mRNA expression and the clinicopathological characteristics. PEDF mRNA expression level was 

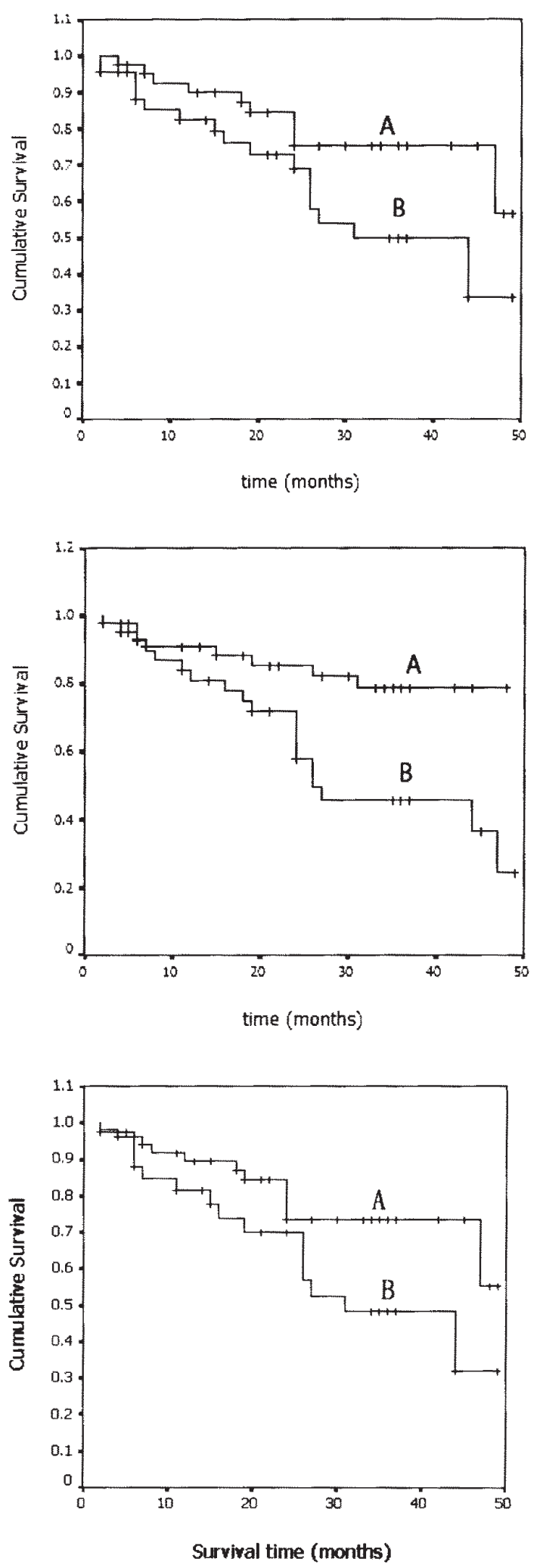

Figure 2. Survival analysis. Top, overall survival of the NSCLC patients based on PEDF levels $(n=91)$. A, PEDF over-expressing tumors $(n=43)$. B, PEDF low expressing tumors $(\mathrm{n}=48)$. The survival curves are significantly separated $(\mathrm{P}=0.0378, \log$-rank test $)$ and the patients with PEDF over-expression have longer survival time than those with low expression. Middle, overall survival based on nodal status of NSCLC patients $(n=91)$. The difference between nodal negative patients $(A, n=49)$ and nodal positive patients (B, $\mathrm{n}=42)$ is significant $(\mathrm{P}=0.0051, \log$-rank test $)$. Bottom, overall survival based on MVD status of NSCLC patients ( $\mathrm{n}=91)$. The difference between low level of MVD (A, n=52) and high level MVD patients (B, n=43) is significant $(\mathrm{P}=0.0434$, log-rank test $)$.
Table V. Relationship between PEDF mRNA expression relative level (PEDF/GAPDH) and clinicopathologic characteristics.

\begin{tabular}{|c|c|c|c|}
\hline Variables & No. & $\begin{array}{c}\text { PEDF mRNA expression }{ }^{\mathrm{a}} \\
(\text { mean } \pm \text { SD })\end{array}$ & P-value \\
\hline \multicolumn{4}{|l|}{ Sex } \\
\hline Male & 13 & $0.47 \pm 0.35$ & \multirow[t]{2}{*}{0.198} \\
\hline Female & 8 & $0.68 \pm 0.35$ & \\
\hline \multicolumn{4}{|l|}{ Histological type } \\
\hline Squamous & 10 & $0.60 \pm 0.35$ & \multirow[t]{2}{*}{0.601} \\
\hline Non-squamous & 11 & $0.51 \pm 0.382$ & \\
\hline \multicolumn{4}{|l|}{ Stage } \\
\hline I-II & 10 & $0.75 \pm 0.39$ & \multirow[t]{2}{*}{0.010} \\
\hline III-IV & 11 & $0.37 \pm 0.22$ & \\
\hline \multicolumn{4}{|l|}{ Tumor staus } \\
\hline $\mathrm{T} 1$ & 6 & $0.87 \pm 0.30$ & \multirow[t]{2}{*}{0.007} \\
\hline $\mathrm{T} 2-4$ & 15 & $0.42 \pm 0.31$ & \\
\hline \multicolumn{4}{|l|}{$\begin{array}{l}\text { Lymph } \\
\text { node status }\end{array}$} \\
\hline No & 8 & $0.68 \pm 0.40$ & \multirow[t]{2}{*}{0.216} \\
\hline $\mathrm{N} 1-3$ & 13 & $0.47 \pm 0.32$ & \\
\hline \multicolumn{4}{|l|}{ Tissue } \\
\hline Tumor & 21 & $0.55 \pm 0.36$ & \multirow[t]{2}{*}{$0.024^{\mathrm{b}}$} \\
\hline $\begin{array}{l}\text { Adjacent } \\
\text { normal tissue }\end{array}$ & 21 & $0.72 \pm 0.26$ & \\
\hline
\end{tabular}

aPEDF mRNA expression derived from real-time quantitative RT-

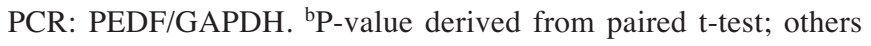
derived from independent t-test.

significantly higher in stage I-II patients than in stage III-IV patients $(0.75 \pm 0.39$ vs $0.37 \pm 0.22 ; \mathrm{P}=0.010$, independent $\mathrm{t}$-test $)$. The levels were also significantly higher in small tumors (T1) than in large tumors (T2-T4) $(0.87 \pm 0.30$ vs $0.42 \pm 0.31$; $\mathrm{P}=0.007$, independent t-test). The relationship between PEDF mRNA expression and sex, histologic type, and lymph node status was not statistically significant $(\mathrm{P}>0.05)$.

\section{Discussion}

PEDF is one of the most potent naturally occurring angiogenesis inhibitor, which is a key factor associated with avascularity of the cornea, vitreous, and the outer retinal layer of the eye (5). PEDF is also an important negative regulator of angiogenic activity of aqueous humour. The current study is the first to report that PEDF was reduced at both protein and mRNA level in non-small cell lung cancer and bore a clinical significance to the patients.

First, the current study has demonstrated that PEDF presents in lung cancer cells, and that it primarily located in 
the cytoplasmic region of the cells, which is in accordance with literature reports. Stromal cells and endothelial cells displayed little staining. Second, PEDF is significantly linked to MVD. Low levels of PEDF is significantly linked to high MVD. The formation of neovasculature is under tight regulation in most healthy tissue and is most probably controlled by the balance between angiogenenic and antiangiogenic factors. The disruption of such a balance might play an essential role in the disregulated development of neovasculature which form the one essential part of cancer development. PEDF was first purified from the conditioned media of human retinal pigment epithelial cells as a neurotrophic factor. The most convincing indication that PEDF may regulate angiogenesis is probably coming from studies on retinopathy, in which PEDF and VEGF dually regulate the development of neovascularization (5). When oxygen is sufficient, the VEGF level decreases but the PEDF level is upregulated to prevent new blood vessels growth (24). The levels of PEDF in diabetic patients can predict the development and progression of retinopathy (25). The regulation of PEDF gene expression and the anti-angiogenic mechanisms of PEDF remain unclear, although Dawson et al demonstrated that hypoxia may reduce the level of PEDF proteins (5). Thus, it appears that this balance is the evolutionary result of adaptation to environment change in normal biology situation. The role of PEDF in solid tumors has not been previously described. The current study suggests that low level of PEDF in human lung tumor cells is inversely associated with MVD and that low level of PEDF is linked to longer survival. This observation has put PEDF on a 'good' list of protein factors in the control of angiongenesis, in lung cancer.

In the current study, we have provided additional evidence that the message level of PEDF is also reduced in NCSLC tumors. We have first successfully developed a quantitative analysis method for PEDF. Using matched tumor and normal tissue samples, it was found that PEDF mRNA expression level in matched normal tissue was significant higher than the cancer tissue (Table $\mathrm{V}, \mathrm{P}<0.05$ ). Furthermore, levels of PEDF message were significantly higher in stage III and stage IV tumors than lower stage tumors. This information provides further supporting data for protein based analysis, in that PEDF protein levels were lower in aggressive tumors, and suggest that the aberration of PEDF expression may be at both protein and transcription level. The second key point here is the provision of direct comparison between matched normal and tumor tissues. The study has clearly shown a reduced level in tumor tissues than in the matched normal tissues. However, the regulation of PEDF gene expression and the anti-angiogenic mechanisms of PEDF are largely unknown. Dawson et al demonstrated that hypoxia could reduce the level of PEDF proteins (5), and that this occurs at the translational or post-translational level.

PEDF has a very interesting dual function feature. In the eyes, it acts as a potent anti-angiogenic factor. It is also an extremely potent inhibitor that is active at low nanomolar concentrations against a wide variety of angiogenic factors, including VEGF (26). It acts directly on endothelial cells and can halt the forming of new vessels by inducing the apoptotic death of endothelial cells that have been stimulated during the formation of new vessels (10).
Targeting angiogenesis has also been postulated to have potential in cancer therapies, including lung cancer. Indeed, encouraging reports have demonstrated that the anti-VEGF antibody, Avastin, can prolong the survival of patients with advanced colon cancer (27) and non-small cell lung cancers (28). These early successes have suggested that targeting angiogenesis has some important role in NSCLC therapies. Given the potential anti-angiogenesis effect and the profound reduction of the factor in lung cancer, particularly in aggressive lung cancer, it is suggested that PEDF may have a good therapeutic value, if it can be successfully engineered and delivered.

In summary, we have shown the PEDF protein and mRNA expression was significantly lower in cancer tissue than in normal tissue. We also found that PEDF expression level was negatively correlated with NSCLC stage and tumor size, and patient survival. Therefore, PEDF to has an anti-angiogenesis role in NSCLC.

\section{Acknowledgements}

We are grateful to Cancer Research Wales (CRW) and Cancer Research UK (CR-UK) for support of this work (WGJ).

\section{References}

1. Lanza RP, Cibelli JB, Blackwell C, et al: Extension of cell lifespan and telomere length in animals clonal from senscent somatic cells. Science 288: 665-669, 2000.

2. Liu H, Ren JG, Cooper WL, et al: Identification of the antibasopermeability effect of pigment epithelium-derived factor and its active site. Proc Natl Acad Sci USA 101: 6605-6610, 2004.

3. Dawson DW, Volpet OV, Gillis P, et al: Pigment epitheliumderived factor: a potent inhibitor of angiogenesis. Science 285: 245-248, 1999.

4. Palmieri D, Watson JM and Rinehart CA: Age-related expression of PEDF/EPC-1 in human endometrial stromal fibroblasts: implications for interactive senescence. Exp Cell Res 247: 142-147, 1999.

5. Folkman J and Shing Y: Angiogenesis. J Biol Chem 267: 10931-10934, 1992.

6. Tombran-Tink J, Chader GG and Johnson LV: PEDF: a pigment epithelium-derived factor with potent neuronal differentiative activity. Exp Eye Res 53: 411-414, 1991.

7. Tombran-Tink J, Mazuruk K, Rodriguez IR, et al: Organization, evolutionary conservation, expression and unusual Alu density of the human gene for pigment epithelium-derived factor, a unique neurotrophic serpin. Mol Vis 2: 11, 1996.

8. Becerra SP, Sagasti A, Spinella P, et al: Pigment epitheliumderived factor behaves like a non-inhibitory serpin. Nerothrophic activity does not require the serpin reactive loop. J Biol Chem 270: 25992-25999, 1995.

9. Mori K, Duh E, Gehlbach P, et al: Pigment epithelium-derived factor inhibits retinal and choroidal neovascularization. J Cell Physiol 188: 253-263, 2001.

10. Stellmach V, Crawford SE, Zhou W, et al: Prevention of ischemiainduced retinopathy by the natural ocular antiangiogenic agent pigment epithelium-derived factor. Proc Natl Acad Sci USA 98: 2593-2597, 2001

11. Raisler BJ, Bems KI, Grant MB, et al: Adeno-associated virus type-2 expression of pigmented epithelum-derived factor or Kringles 1-3 of angiostatin reduce retinal neovascularization. Proc Natl Acad Sci USA 99: 8909-8914, 2002.

12. Houenou LJ, D'Costa AP, Li L, et al: Pigment epithelial-derived factor promotes the survival and differentiation of developing spinal motor neurons. J Comp Neurol 412: 506-514, 1999.

13. Uehara H, Miyamoto M, Kato K, et al: Expression of pigment epithelium-derived factor decrease liver metastasis and correlates with favorable prognosis for patients with ductal pancreatic adenocarcinoma. Cancer Res 64: 3533-3537, 2004. 
14. Zhang LJ, Chen M, Ke Y, Mansel RE and Jiang WG: Downregulation of PEDF in lung cancer cells impact on lung cancer induced angiogenesis in vitro. Oncol Rep 14: 1615-1620, 2005.

15. Sobin LH and Fleming ID: TNM Classification of Malignant Tumors. 5th edition. Union Internationale Contre le Cancer and the American Joint Committee on Cancer. Cancer 80: 1803-1804, 1997.

16. Travis WD: WHO Histological Typing of Lung and Pleural Tumors. WHO, Geneva, 1999.

17. Kumazaki K, Nakayama M, Suehara N, et al: Expression of vascular endothelial growth factor, and their receptors Flt-1 and KDR in human placenta under pathologic conditions. Hum Pathol 33: 1069-1077, 2002.

18. Mineo TC, Ambrogi V, Baldi A, et al: Prognostic impact of VEGF, CD31, CD34 and CD105 expression and tumor vessel invasion after radical surgery for IB-IIA non-small cell lung cancer. J Clin Pathol 57: 591-597, 2004.

19. Martin TA, Parr C, Davies G, Matsumoto K, Nakamura T, Mansel RE and Jiang WG: NK4 reduced HGF/SF and fibroblast induced breast tumour growth. Carcinogenesis 24: 1317-1325, 2003.

20. Jiang WG, Watkins G, Douglas-Jones A and Mansel RE: Psoriasin (S100A7) is aberrantly expressed in human breast cancer and is related to clinical outcomes. Int J Oncol 25: 81-86, 2004.
21. Zhang LJ, Chen M, Ke Y, Mansel RE and Jiang WG: Expression of placenta growth factor (PIGF) in human non-small cell lung cancer and its clinical and prognostic signficance. World J Surg Oncol 3: 68, 2005.

22. Gibson UEM, Heid CA and Willian PM: A novel method for real-time quantitative RT-PCR. Genome Res 6: 995-1001, 1996.

23. Parr $\mathrm{C}$ and Jiang WG: The Notch receptors, Notch-1 and Notch-2, in human breast cancers. Int J Mol Med 14: 779-786, 2004.

24. Gao G, Li Y, Zhang D, et al: Unbalanced expression of VEGF and PEDF in ischemia-induced retinal neovascularization. FEBS Lett 489: 270-276, 2001.

25. Boehm BO, Lang G, Volpert O, et al: Low content of the natural ocular anti-angiogenic agent pigment epithlium-derived factor (PEDF) in aqueous humor predicts progression of diabietic retinopathy. Diabetologia 46: 394-400, 2003.

26. Chader GJ: PEDF: raising both hopes and questions in controllin angiogenesis. Proc Natl Acad Sci USA 98: 2122-2124, 2001.

27. Kabbinavar F, Hurwitz HI, Fehrenbacher L, Meropol NJ, Novotny WF, Lieberman G, Griffing S and Bergsland E: Phase II, randomized trial comparing bevacizumab plus fluorouracil (FU)/ leucovorin (LV) with FU/LV alone in patients with metastatic colorectal cancer. J Clin Oncol 21: 60-65, 2003.

28. Sandler AB, Johnson DH and Herbst RS: Anti-vascular endothelial growth factor monoclonals in non-small cell lung cancer. Clin Cancer Res 10: 4258S-4262S, 2004. 